\title{
Dipyridamole plus aspirin versus aspirin alone in the secondary prevention after TIA or stroke: a meta-analysis by risk
}

PHA Halkes, LJ Gray, PMW M Bath, HC Diener, B Guiraud-Chaumeil, FM Yatsu and A Algra

J. Neurol. Neurosurg. Psychiatry published online 6 Oct 2008; doi:10.1136/jnnp.2008.143875

Updated information and services can be found at:

http://jnnp.bmj.com/cgi/content/abstract/jnnp.2008.143875v2

\section{These include:}

Rapid responses You can respond to this article at:

http://jnnp.bmj.com/cgi/eletter-submit/jnnp.2008.143875v2

Email alerting Receive free email alerts when new articles cite this article - sign up in the box at the service top right corner of the article

\section{Notes}

Online First contains unedited articles in manuscript form that have been peer reviewed and accepted for publication but have not yet appeared in the paper journal (edited, typeset versions may be posted when available prior to final publication). Online First articles are citable and establish publication priority; they are indexed by PubMed from initial publication. Citations to Online First articles must include the digital object identifier (DOIs) and date of initial publication.

To order reprints of this article go to:

http://journals.bmj.com/cgi/reprintform

To subscribe to Journal of Neurology, Neurosurgery, and Psychiatry go to:

http://journals.bmj.com/subscriptions/ 
Dipyridamole plus aspirin versus aspirin alone in the secondary prevention after TIA or stroke: a meta-analysis by risk.

Halkes PHA, Gray LJ, Bath PMW, Diener H-C, Guiraud-Chaumeil B, Yatsu FM, Algra A

From the Department of Neurology, Rudolf Magnus Institute of Neuroscience and Julius Center for Health Sciences and Primary Care, University Medical Center Utrecht (P.H., A.A.), Utrecht, The Netherlands; the University of Nottingham (L.G., P.B.), Nottingham, U.K.; the University of Essen (H-C.D.), Essen, Germany; C H U de Toulouse-Purpan (B.G-C), Toulouse, France; the University of Texas (F.Y.), Houston, USA

\section{Corresponding author:}

Prof. P.M.W. Bath

Division of Stroke Medicine

University of Nottingham City Hospital Campus

Nottingham NG5 1PB

United Kingdom

Telephone: 01158231768 Fax: 01158231767

e-mail: philip.bath@ nottingham.ac.uk

Word count (without abstract, tables and references): 2355

Key words: stroke, platelet aggregation inhibitors, secondary prevention 


\begin{abstract}
Objectives: Our aim was to study the effect of combination therapy with aspirin and dipyridamole $(\mathrm{A}+\mathrm{D})$ over aspirin alone (ASA) in secondary prevention after transient ischemic attack or minor stroke of presumed arterial origin and to perform subgroup analyses to identify patients that might benefit most from secondary prevention with A+D.

Data sources: The previously published meta-analysis of individual patient data was updated with data from ESPRIT $(\mathrm{N}=2,739)$; trials without data on the comparison of $\mathrm{A}+\mathrm{D}$ versus ASA were excluded.

Review methods: A meta-analysis was performed using Cox regression, including several subgroup analyses and following baseline risk stratification.

Results: A total of 7,612 patients (5 trials) were included in the analyses, 3,800 allocated to A+D and 3,812 to ASA alone. The trial-adjusted hazard ratio for the composite event of vascular death, non-fatal myocardial infarction and non-fatal stroke was $0.82(95 \%$ confidence interval 0.72-0.92). Hazard ratios did not differ in subgroup analyses based on age, sex, qualifying event, hypertension, diabetes, previous stroke, ischemic heart disease, aspirin dose, type of vessel disease and dipyridamole formulation, nor across baseline risk strata as assessed with two different risk scores. A+D were also more effective than ASA alone in preventing recurrent stroke, HR 0.78 (95\% CI 0.68 - 0.90).

Conclusion: The combination of aspirin and dipyridamole is more effective than aspirin alone in patients with TIA or ischemic stroke of presumed arterial origin in the secondary prevention of stroke and other vascular events. This superiority was found in all subgroups and was independent of baseline risk.
\end{abstract}




\section{Introduction}

After a transient ischemic attack (TIA) or stroke of presumed arterial origin patients have an annual risk of a serious vascular event (recurrent stroke, myocardial infarction or death from vascular cause) of $9 \%$ in population based studies. ${ }^{1}$ Treatment with aspirin, in a dose between 30 and $300 \mathrm{mg}$ daily, reduces this risk by $13-22 \% .^{2-4}$ In one study, treatment with dipyridamole alone was found to reduce risk by a similar amount. ${ }^{5}$ Although clopidogrel was marginally superior to aspirin in the CAPRIE trial, no statistically significant difference was seen in the subset of patients with previous ischemic stroke (average event rate per year $7.15 \%$ for clopidogrel versus $7.71 \%$ for aspirin, relative-risk reduction of $7.3 \%$ (95\% CI -5.7-18.7). ${ }^{6}$ Furthermore, there is no indication for an additional benefit of combining aspirin and clopidogrel as compared with either drug alone, ${ }^{7 ; 8}$ or for anticoagulation treatment with any INR range. ${ }^{9-13}$ The combination of aspirin and dipyridamole has been tested in several trials although early results did not show any beneficial effect over aspirin alone. ${ }^{14-17}$ In contrast, the 'Second European Stroke Prevention Study' (ESPS 2) found that the addition of dipyridamole (extended release $200 \mathrm{mg}$ twice daily) to aspirin (50 $\mathrm{mg}$ daily) reduced serious vascular events by $22 \%$ (95\% confidence interval [CI] 9-33\%) in comparison with aspirin alone. ${ }^{5 ; 18}$ The positive results of two meta-analyses on this comparison were based mainly on the results of ESPS 2, which was by far the largest trial included. ${ }^{19 ; 20}$ Subsequently, the European/Australasian Stroke Prevention in Reversible Ischemia Trial $(\text { ESPRIT })^{21}$ confirmed the results of ESPS 2; the hazard ratio for the primary outcome event (vascular death, recurrent stroke, myocardial infarction, or major bleeding complication) was 0.80 (95\% CI 0.66-0.98). ${ }^{21}$

We have updated the earlier meta-analysis based on individual patient data (IPD) ${ }^{20}$ with the inclusion of ESPRIT and aimed to identify patients who may benefit most from the combination of aspirin and dipyridamole. In particular, we wished to assess whether a patient's baseline risk would modify the efficacy of combination therapy. 


\section{Methods}

Searching and selection

The search strategy to identify all eligible randomized controlled trials on the effectiveness of dipyridamole in the secondary prevention after TIA or minor stroke of arterial origin has been described previously. ${ }^{20}$ We selected trials which compared, at a minimum, the combination therapy of aspirin and dipyridamole with aspirin alone. The principal investigators of each included trial shared individual patient data for use in the current analysis.

\section{Data abstraction}

Data from the different trials were merged into a single data set for analysis. This database contained information on demography (age, sex), qualifying event (TIA or stroke, clinical features of the event, findings on brain imaging), vascular risk profile (history by of hypertension, diabetes, ischemic heart disease or stroke and blood pressure at baseline), prescribed trial medication (dose of aspirin and formulation of dipyridamole) and the occurrence of serious events ((vascular) death, myocardial infarction or stroke) during the trial. On the basis of findings on brain imaging (CT or MRI) and clinical features, we classified patients as having small or large vessel disease. If a relevant ischemic lesion was detected with imaging, classification was based on the characteristics of this lesion. If no lesion was detected, we used clinical symptoms for classification as in previous studies. $^{22 ; 23}$

\section{Study characteristics}

The primary outcome event was the composite of death from all vascular causes, nonfatal stroke and non-fatal myocardial infarction. Secondary outcome events were the composite of death from all vascular causes or non-fatal stroke, all death, death from vascular causes, fatal and non-fatal stroke, and fatal and non-fatal myocardial infarction. Prespecified subgroup analyses for the primary outcome event were performed according to age ( $<65$ years vs. $\geq 65$ years), sex (male vs. female), qualifying event (TIA vs. stroke), type of vessel disease in qualifying event (small vs. large), dose of aspirin ( $<75 \mathrm{mg}$ vs. $\geq 75 \mathrm{mg}$ ), formulation of dipyridamole (immediate vs. extended release), time between qualifying event and randomization ( $<1$ week vs 1 week-1 month vs 1-6 months) and history of hypertension, diabetes, stroke or ischemic heart disease.

In addition we did a subgroup analysis according to baseline risk as assessed with two different risk models. The first model used three risk factors: age 65 years or older, stroke as a qualifying event and a history of hypertension; the risk of stroke increased with an increasing number of risk factors (0-3) in the previous IPD meta-analysis. ${ }^{20}$ The area under the receiver operator characteristics curve (AUC-ROC) for this model in the current data set was 0.59 (95\% CI 0.57-0.60) The second model was developed with data from the Dutch TIA Trial (DTT), a secondary stroke prevention trial with a factorial design comparing two doses of aspirin, and atenolol, with placebo. ${ }^{24 ; 25}$ We used those characteristics identified previously to be associated with new vascular events ${ }^{26}$ and that were available in the present dataset, resulting in a risk score: $0.532 * \operatorname{sex}(0$ : female, 1 : male $)+0.037 *$ age $($ years $)+0.757 *$ diabetes $(0:$ no, 1 : yes $)+0.383 *$ history of ischemic heart disease $(0:$ no, 1 : yes $)+0.007 *$ systolic blood pressure $(\mathrm{mm} \mathrm{Hg})$; its AUC-ROC was 0.62 (95\% CI 0.60-0.64). Based on this risk score, patients were divided into 5 risk- 
quintiles. Subgroup analyses were performed based on the different risk groups from these two models. The numbers needed to treat were calculated for each subgroup. In Table 1 a cross-tabulation for the risk scores from the two models is shown to give an impression of the agreement of risk between the models.

Table 1. Cross-tabulation for the risk scores from the two models used (both scores known for 5,967 patients)

\begin{tabular}{lcccc}
\hline Risk score quintiles $^{*}$ & \multicolumn{4}{c}{ Risk score based on 3 risk factors } \\
\hline & $\mathbf{0}$ & $\mathbf{1}$ & $\mathbf{2}$ of factors present \\
$\mathbf{1}$ & 237 & 594 & 365 & $\mathbf{3}$ \\
$\mathbf{2}$ & 116 & 392 & 521 & 164 \\
$\mathbf{3}$ & 58 & 273 & 556 & 310 \\
$\mathbf{4}$ & 15 & 180 & 547 & 449 \\
$\mathbf{5}$ & 2 & 81 & 469 & 636 \\
\hline
\end{tabular}

*: quintiles based on risk score calculated with formula: $0.532 *$ sex (0: female, 1: male) $+0.037 *$ age (years $)+0.757 *$ diabetes $(0:$ no, $1:$ yes $)+0.383 *$ history of ischemic heart disease $(0:$ no, $1:$ yes $)+0.007 *$ systolic blood pressure $(\mathrm{mm} \mathrm{Hg})$ $\dagger:$ risk factors: age 65 years or older, stroke as a qualifying event and a history of hypertension

Quantitative data synthesis

Data were analyzed according to the intention-to-treat principle. The occurrence of outcome events was compared between patients allocated to combined aspirin and dipyridamole versus patients allocated to aspirin in terms of the hazard ratio (HR, with 95\% CI), calculated with Cox proportional hazard modeling. To adjust for a possible heterogeneity between the trials we stratified the Cox model with trial as the stratification factor. ${ }^{27}$ All analyses were in duplicate performed, independently, by two investigators (PH, LG).

Analyses were performed with Stata version 8 and SPSS version 12.0.02.

\section{Statement of responsibility}

The authors had full access to the data and take responsibility for its integrity. All authors have read and agree to the manuscript as written. The Corresponding Author has the right to grant on behalf of all authors and does grant on behalf of all authors, an exclusive licence (or non exclusive for government employees) on a worldwide basis to the BMJ Publishing Group Ltd and its Licensees to permit this article (if accepted) to be published in the Journal of Neurology, Neurosurgery \& Psychiatry editions and any other BMJPGL products to exploit all subsidiary rights, as set out in our licence. 


\section{Results}

Trial flow and study characteristics

Five randomized controlled trials comparing the combination of aspirin and dipyridamole with aspirin alone in the secondary prevention after cerebral ischemia of arterial origin were identified (Figure 1). ${ }^{5 ; 14-16 ; 21}$ In two trials, randomization was only done between combination therapy and aspirin alone; ${ }^{16 ; 21}$ whereas the other trials also compared combination therapy with placebo, ${ }^{5 ; 14 ; 15}$ or dipyridamole alone. ${ }^{5}$ The dose of aspirin was fixed in four trials: $25 \mathrm{mg}$ twice daily, ${ }^{5} 300 \mathrm{mg}$ three times daily, ${ }^{14} 325 \mathrm{mg}$ three times daily ${ }^{16}$ or $330 \mathrm{mg}$ three times daily. ${ }^{15}$ In ESPRIT the dose of aspirin was left to the discretion of the treating physician, provided it was between 30 and $325 \mathrm{mg}$ daily. The dose of dipyridamole was $50 \mathrm{mg}$ three times daily ${ }^{14}, 75 \mathrm{mg}$ three $^{15}$ or four $^{16}$ times daily or $200 \mathrm{mg}$ twice daily. ${ }^{5 ; 21}$ In three trials all patients used the immediate release formulation of dipyridamole, ${ }^{14-16}$ and in one trial all patients used the extended release formulation. ${ }^{5}$ In ESPRIT the majority of patients (83\%) used the extended release formulation and the remaining patients used the immediate release formulation. ${ }^{21}$ One trial only included patients with a TIA; ${ }^{16}$ the others also included patients with a minor stroke. ${ }^{5 ; 14 ; 15 ; 21}$ The five trials included 3,800 patients allocated to combined aspirin and dipyridamole, and 3,812 patients allocated to aspirin alone. Table 2 shows the baseline characteristics for the different trials and for the combined data. Apart from the differences mentioned above (dose of aspirin, formulation of dipyridamole and type of qualifying event), the main difference between the samples was that the mean age was higher in ESPS 2 (mean age 67 versus 62-63 in the other trials) and the fact that in the Toulouse trial there were more males included (more than $80 \%$ versus less than $70 \%$ in the others). In total, almost twothirds of patients were male with a mean age of 65 years. In the majority the qualifying event was a stroke. There were no major differences in the prevalence of vascular risk factors between the different trials. The mean length of follow-up was 2.6 years (range 0 8.21 years). 
Table 2. Trial characteristics for included trials

*: mean (SD), FU: duration of follow-up (months), Trt.: allocated treatment, N: number of patients, QE: stroke as qualifying event, Stroke: stroke before qualifying event, HT: history of hypertension, SBP: systolic blood pressure, DBP: diastolic blood pressure, IHD: history of ischemic heart disease, DM: history of diabetes mellitus, AD: aspirin plus dipyridamole, A: aspirin, $\dagger:$ total limited to the trials with data for this characteristic

\begin{tabular}{|c|c|c|c|c|c|c|c|c|c|c|c|c|}
\hline $\begin{array}{l}\text { Trial } \\
\text { Year }\end{array}$ & $\mathrm{FU}$ & Trt. & $\mathrm{N}$ & Male (\%) & $\mathrm{Age}^{*}$ & $\mathrm{QE}(\%)$ & Stroke $(\%)$ & $\mathrm{HT}(\%)$ & $\mathrm{SBP}^{*}$ & $\mathrm{DBP}^{*}$ & IHD & $\mathrm{DM}$ \\
\hline Toulouse & $36-72$ & AD & 137 & $112(82)$ & $62(10)$ & $81(60)$ & - & - & - & - & - & - \\
\hline $1982^{14}$ & & $\mathbf{A}$ & 147 & $126(86)$ & $62 \quad(9)$ & $92(63)$ & - & - & - & - & - & - \\
\hline AICLA & 36 & AD & 202 & $146(72)$ & $63(10)$ & $169(84)$ & - & $119(59)$ & $149(20)$ & $90(10)$ & - & $51(25)$ \\
\hline $1983^{15}$ & & $\mathbf{A}$ & 198 & $131(66)$ & $63(10)$ & $68(85)$ & - & $129(65)$ & $150(21)$ & $90(12)$ & - & $44(22)$ \\
\hline ACSSG & $24-60$ & AD & 448 & $306(68)$ & $63(10)$ & 0 & - & $214(48)$ & - & - & - & $70(16)$ \\
\hline $1985^{16}$ & & $\mathbf{A}$ & 442 & $288(65)$ & $63(10)$ & 0 & - & $205(46)$ & - & - & - & 49 (11) \\
\hline ESPS 2 & 24 & AD & 1650 & $956(58)$ & $67(11)$ & $1246(76)$ & $439(27)$ & $979(60)$ & $150(22)$ & 85 (12) & $573(35)$ & $254(15)$ \\
\hline $1996^{5}$ & & $\mathbf{A}$ & 1649 & $956(58)$ & $67(11)$ & $1257(76)$ & $464(28)$ & $983(60)$ & $151(21)$ & $86(11)$ & $571(35)$ & $240(15)$ \\
\hline ESPRIT & mean & AD & 1363 & 897 (66) & $63(11)$ & 895 (66) & 159 (12) & $814(60)$ & $152(24)$ & $86(12)$ & $179(13)$ & 260 (19) \\
\hline $2006^{21}$ & 42 & $\mathbf{A}$ & 1376 & $892(65)$ & $63(11)$ & $921(67)$ & $155(11)$ & 817 (59) & $152(23)$ & $86(12)$ & $177(13)$ & 252 (18) \\
\hline Total & 31 & $\begin{array}{l}\text { AD } \\
\text { A }\end{array}$ & $\begin{array}{l}3800 \\
3812 \\
\end{array}$ & $\begin{array}{l}2417(64) \\
2393(63)\end{array}$ & $\begin{array}{l}65(11) \\
65(11)\end{array}$ & $\begin{array}{l}2391(63) \\
2438(64)\end{array}$ & $\begin{array}{l}598(20)^{\dagger} \\
619(21)^{\dagger}\end{array}$ & $\begin{array}{l}2126(58)^{\dagger} \\
2134(58)^{\dagger}\end{array}$ & $\begin{array}{l}151(23)^{\dagger} \\
151(22)^{\dagger}\end{array}$ & $\begin{array}{l}86(12)^{\dagger} \\
86(12)^{\dagger}\end{array}$ & $\begin{array}{l}749(25)^{\dagger} \\
748(25)^{\dagger}\end{array}$ & $\begin{array}{l}635(17)^{\dagger} \\
585(16)^{\dagger}\end{array}$ \\
\hline
\end{tabular}


Quantitative data synthesis

In the combined aspirin and dipyridamole group 475 patients $(12.5 \%)$ had a primary outcome event, compared with 579 patients $(15.2 \%)$ in the aspirin group, resulting in an adjusted HR of 0.82 (95\% CI 0.72-0.92) (Table 3). The adjusted HR for the composite event of death from vascular cause or non-fatal stroke was 0.81 (95\% CI 0.72-0.92), that for vascular death 0.96 (95\% CI 0.78-1.18) and for recurrent stroke 0.78 (95\% CI 0.68$0.90)$. The number needed to treat (1/absolute risk reduction*100) with aspirin plus dipyridamole instead of aspirin alone to prevent one serious vascular event to happen is 100 per year. Figure 2 shows the time-to-event curve for the primary outcome event.

Table 3. Occurrence of outcome events, according to treatment

\begin{tabular}{lcccc}
\hline & $\begin{array}{c}\text { ASA+DIP } \\
\mathrm{n}=3800\end{array}$ & $\begin{array}{c}\text { ASA } \\
\mathrm{n}=3812\end{array}$ & HR & 95\% CI \\
\hline $\begin{array}{l}\text { Person-years of } \\
\text { observation }\end{array}$ & 9441 & 9396 & & \\
$\begin{array}{l}\text { Vascular death, non- } \\
\text { fatal stroke or non-fatal } \\
\text { myocardial infarction }\end{array}$ & $475(12.5 \%)$ & $579(15.2 \%)$ & 0.82 & $0.72-0.92$ \\
$\begin{array}{l}\text { Vascular death or non- } \\
\text { fatal stroke }\end{array}$ & 434 & & & \\
All death & & 528 & 0.81 & $0.72-0.92$ \\
Vascular death & 358 & 360 & 1.01 & $0.87-1.17$ \\
Recurrent stroke & 175 & 187 & 0.96 & $0.78-1.18$ \\
Myocardial infarction & 341 & 429 & 0.78 & $0.68-0.90$ \\
\hline
\end{tabular}

ASA+DIP: aspirin and dipyridamole, ASA: aspirin, MI: myocardial infarction HR: hazard ratio, adjusted for trial; $C I=$ confidence interval

Figure 3 shows the results of the subgroup analyses according to age, sex, qualifying event, hypertension, diabetes, stroke, ischemic heart disease, dose of aspirin, type of vessel disease, formulation of dipyridamole and interval between qualifying event and randomization for the primary outcome event. No major differences between the subgroups were found (smallest $\mathrm{p}$ value for interaction 0.14 ). The only slight differences in the estimated hazard ratios for the subgroups confirm the superior efficacy of aspirin plus dipyridamole in all groups. Figure 4 shows the subgroup analyses according to the number of risk factors present at baseline (known for 7,302 patients, panel A) and according to the risk score derived from the DTT-risk model (known for 5,989 patients, panel B). The HRs were broadly similar in all risk groups and not different from the overall HR (smallest $p$ value for interaction 0.11 ). The numbers needed to treat with dipyridamole and aspirin instead of aspirin alone to prevent one major vascular event per year are shown as well; no major differences were found here either. 


\section{Discussion}

This individual patient data meta-analysis confirms that the combination of aspirin and dipyridamole is more effective than aspirin alone in secondary vascular prevention after TIA or minor stroke from arterial origin. From figure 2 we can conclude that the advantage of the combination therapy of aspirin plus dipyridamole starts early on and remains present over time. Importantly, analyses in prognostic subgroups, including age, sex and vascular history, found no differential effects between groups of patients whereas currently there may be a selection of patients who receive dipyridamole in addition to aspirin. Quantitatively, combined aspirin and dipyridamole reduce vascular events by $18 \%$, and stroke by $22 \%$, as compared with aspirin alone, results which do not differ materially from earlier meta-analyses, ${ }^{19-21}$ In contrast, dual antiplatelet therapy had no advantage over aspirin in preventing total death, vascular death, or myocardial infarction; importantly, the combination of aspirin and dipyridamole did not increase the incidence of myocardial infarction.

The number needed to treat found in this meta-analysis is 100 per year, which is about the same as the number needed to treat for aspirin versus placebo. Whether this NNT is costeffective for aspirin plus dipyridamole should be formally assessed in a cost-effectiveness analysis.

The risk models we used did not have a strong discriminatory ability with regard to prediction of major vascular events, as is obvious from the AU ROCs (0.59 and 0.62 respectively). Unfortunately, there are no stronger prediction models for vascular events after a TIA or minor stroke. ${ }^{28}$ Moreover, we could only use those variables that were available in the included trials.

Previous subgroup analyses in ESPS 2 suggested that the relative efficacy for combination therapy was greater in patients at high risk of recurrence than those at lower risk. $^{29 ; 30}$ In our larger individual patient data meta-analysis, in contrast, we found that relative efficacy for vascular events was not related to the estimated baseline risk. Moreover, the numbers needed to treat varied between the different risk groups, but there was no indication that these numbers were higher in low risk patients. The independence of relative risk reduction from baseline risk is important since the risk of recurrence has fallen with time in patients randomized to aspirin (overall, $6.1 \%$ per year versus $4.3 \%$ per year in ESPRIT), this presumably reflecting improved non-antiplatelet prophylaxis. The main difference between the five trials was the prescribed trial medication. Aspirin doses varied reflecting historical and geographical variations in practice. Since lower doses of aspirin (30-75 mg daily) are no less effective at preventing vascular recurrence than higher doses, ${ }^{2 ; 24}$ this variation is unlikely to have influenced the results. Similarly, the dose and formulation of dipyridamole varied between the trials; older studies used short acting (immediate release) dipyridamole give 3-4 times per day ${ }^{14-16}$ whereas all patients in ESPS 2 and most (83\%) in ESPRIT received extended release dipyridamole twice daily. ${ }^{5 ; 21}$ This difference might explain, in part, the difference seen in efficacy between older and newer trials with dipyridamole. However, our subgroup analyses do not show any differences in efficacy of aspirin and dipyridamole between different doses of aspirin or different formulations of dipyridamole.

The results of meta-analyses may be confounded if data from unpublished trials are not available for inclusion; notably, these trials are more likely to be neutral or negative in 
outcome leading to publication bias. Missing trials have never been reported to us following our previous meta-analyses ${ }^{19 ; 20}$ so it is very unlikely that any medium-sized to large trials are missing here. However, data on risk factors were not available for all five trials so the subgroup analyses involve fewer patients for some analyses. Nevertheless, meta-analysis allows the total evidence to be assessed and the use of individual patient data, as here, is superior to the use of summary group data. ${ }^{31}$

The superiority of combination aspirin and dipyridamole over aspirin alone in secondary vascular prevention after TIA or stroke is now well supported. The hazard ratio found in this individual patient data meta-analysis is consistent with the two largest clinical trials and does not appear to differ in subgroups of patients. Combination therapy with aspirin and dipyridamole should be preferred over aspirin alone in all patients after a TIA or minor stroke of presumed arterial origin, as supported by several national guidelines. 


\section{Competing interests}

A.A., P.B., H-C.D, P.H. and J.Y. have received grants or honoraria from Boehringer Ingelheim (manufacturer of dipyridamole) and H-C.D. has received grants or honoraria form Sanofi-Aventis (manufacturer of clopidogrel).

Most authors have been involved in the trials included in this analysis: Toulouse (B.GC.), ACSSG (J.Y.), ESPS 2 (H-C.D.), ESPRIT (A.A., P.H., P.B.).

This study was initiated, analyzed, interpreted and funded independently of any pharmaceutical company.

\section{Acknowledgements}

We would like to acknowledge Prof. J. van Gijn, Prof. L.J. Kappelle and Prof. P.J.

Koudstaal for their valuable comments on the manuscript.

\section{Figure legends}

Figure 1. Trial flow

Figure 2. Time-to-event curve for the primary outcome event

Figure 3. Subgroup analyses according to risk factors

a: number of trials for which the characteristic is known; $b$ : number of patients in subgroup; $c$ : stroke before qualifying event; $d$ : history of ischemic heart disease; $e$ : qualifying event

Figure 4. Subgroup analyses based on risk groups; A: risk groups based on presence of 3 risk factors; B: groups based on DTT-risk model

*: risk on a major vascular event (vascular death, nonfatal stroke or nonfatal myocardial infarction) per year; NNT: numbers needed to treat with aspirin and dipyridamole instead of with aspirin alone to prevent one major vascular event per year; HR: hazard ratio 


\section{Reference List}

1. Warlow CP. Secondary prevention of stroke. Lancet 1992;339:724-7.

2. Algra A, van Gijn J. Aspirin at any dose above $30 \mathrm{mg}$ offers only modest protection after cerebral ischaemia. J.Neurol.Neurosurg.Psychiatry 1996;60:197-9.

3. Algra A, van Gijn J. Cumulative meta-analysis of aspirin efficacy after cerebral ischaemia of arterial origin. J.Neurol.Neurosurg.Psychiatry 1999;66:255.

4. Antithrombotic Trialists' Collaboration. Collaborative meta-analysis of randomised trials of antiplatelet therapy for prevention of death, myocardial infarction, and stroke in high risk patients. BMJ 2002;324:71-86.

5. Diener HC, Cunha L, Forbes C, et al. European Stroke Prevention Study. 2.

Dipyridamole and acetylsalicylic acid in the secondary prevention of stroke. J.Neurol.Sci. 1996;143:1-13.

6. CAPRIE Steering Committee. A randomised, blinded, trial of clopidogrel versus aspirin in patients at risk of ischaemic events (CAPRIE). Lancet 1996;348:1329-39.

7. Bhatt DL, Fox KA, Hacke W, et al. Clopidogrel and aspirin versus aspirin alone for the prevention of atherothrombotic events. N.Engl.J.Med. 2006;354:1706-17.

8. Diener HC, Bogousslavsky J, Brass LM, et al. Aspirin and clopidogrel compared with clopidogrel alone after recent ischaemic stroke or transient ischaemic attack in high-risk patients (MATCH): randomised, double-blind, placebo-controlled trial. Lancet 2004;364:331-7.

9. The Stroke Prevention in Reversible Ischaemia Trial (SPIRIT) Study Group. A randomized trial of anticoagulants versus aspirin after cerebral ischemia of presumed arterial origin. Ann.Neurol. 1997;42:857-65.

10. Mohr JP, Thompson JLP, Lazar RM, et al, for the Warfarin-Aspirin Recurrent Stroke Study Group. A comparison of warfarin and aspirin for the prevention of recurrent ischemic stroke. N.Engl.J.Med. 2001;345:1444-51.

11. Chimowitz MI, Lynn MJ, Howlett-Smith H, et al, for the Warfarin-Aspirin Symptomatic Intracranial Disease Trial Investigators. Comparison of warfarin and aspirin for symptomatic intracranial arterial stenosis. N.Engl.J.Med. 2005;352:1305-16.

12. Algra A, De Schryver ELLM, van Gijn J, et al. Oral anticoagulants versus antiplatelet therapy for preventing further vascular events after transient ischaemic attack or minor stroke of presumed arterial origin. Cochrane.Database.Syst.Rev. 2006;3:CD001342.

13. The ESPRIT Study Group. Medium intensity oral anticoagulants versus aspirin after cerebral ischaemia of arterial origin (ESPRIT): a randomised controlled trial. Lancet Neurol. 2007;6:115-24. 
14. Guiraud-Chaumeil B, Rascol A, David J, et al. Prévention des récidives des accidents vasculaires cérébraux ischémiques par les anti-agrégants plaquettaires. Résultats d'un essai thérapique controlé de 3 ans. Rev.Neurol.(Paris) 1982;138:367-85.

15. Bousser MG, Eschwege E, Haguenau M, et al. "AICLA" controlled trial of aspirin and dipyridamole in the secondary prevention of athero-thrombotic cerebral ischemia. Stroke 1983;14:5-14.

16. American-Canadian Co-operative Study group. Persantine Aspirin Trial in cerebral ischemia. Part II: Endpoint results. Stroke 1985;16:406-15.

17. Kaye, J. A. A trial to evaluate the relative roles of dipyridamole and aspirin in the prevention of deep vein thrombosis in stroke patients. Bracknell, Berkshire, Boehringer Ingelheim (internal report) . 1990.

18. European Stroke Prevention Study 2. Efficacy and safety data. J.Neurol.Sci. 1997;151 Suppl:S1-77.

19. Algra A, van Gijn J, Koudstaal PJ. Secondary prevention after cerebral ischaemia of presumed arterial origin: is aspirin still the touchstone? J.Neurol.Neurosurg.Psychiatry 1999;66:557-9.

20. Leonardi-Bee J, Bath PM, Bousser MG, et al. Dipyridamole for preventing recurrent ischemic stroke and other vascular events: a meta-analysis of individual patient data from randomized controlled trials. Stroke 2005;36:162-8.

21. The ESPRIT Study Group. Aspirin plus dipyridamole versus aspirin alone after cerebral ischaemia of arterial origin (ESPRIT): randomised controlled trial. Lancet 2006;367:1665-73.

22. Ariesen MJ, Algra A, Kappelle LJ. Antiplatelet drugs in the secondary prevention after stroke: differential efficacy in large versus small vessel disease? A subgroup analysis from ESPS-2. Stroke 2006;37:134-8.

23. Kappelle LJ, van Latum JC, van Swieten JC, et al, for the Dutch TIA Trial Study Group. Recurrent stroke after transient ischaemic attack or minor ischaemic stroke: does the distinction between small and large vessel disease remain true to type?

J.Neurol.Neurosurg.Psychiatry 1995;59:127-31.

24. The Dutch TIA Trial Study Group. A comparison of two doses of aspirin (30 mg vs. 283 $\mathrm{mg}$ a day) in patients after a transient ischemic attack or minor ischemic stroke.

N.Engl.J.Med. 1991;325:1261-6.

25. The Dutch TIA Trial Study Group. Trial of secondary prevention with atenolol after transient ischemic attack or nondisabling ischemic stroke. Stroke 1993;24:543-8.

26. The Dutch TIA Trial Study Group. Predictors of major vascular events in patients with a transient ischemic attack or nondisabling stroke. Stroke 1993;24:527-31.

27. Smith CT, Williamson PR, Marson AG. Investigating heterogeneity in an individual patient data meta-analysis of time to event outcomes. Stat.Med. 2005;24:1307-19. 
28. Dippel DW, Koudstaal PJ. We need stronger predictors of major vascular events in patients with a recent transient ischemic attack or nondisabling stroke. Dutch TIA Trial Study Group. Stroke 1997;28:774-6.

29. Diener HC. Modified-release dipyridamole combined with aspirin for secondary stroke prevention. Aging Health 2005;1:19-26.

30. Sacco RL, Sivenius J, Diener HC. Efficacy of aspirin plus extended-release dipyridamole in preventing recurrent stroke in high-risk populations. Arch.Neurol. 2005;62:403-8.

31. Stewart LA, Parmar MK. Meta-analysis of the literature or of individual patient data: is there a difference? Lancet 1993;341:418-22. 
Figure 1. Trial flow

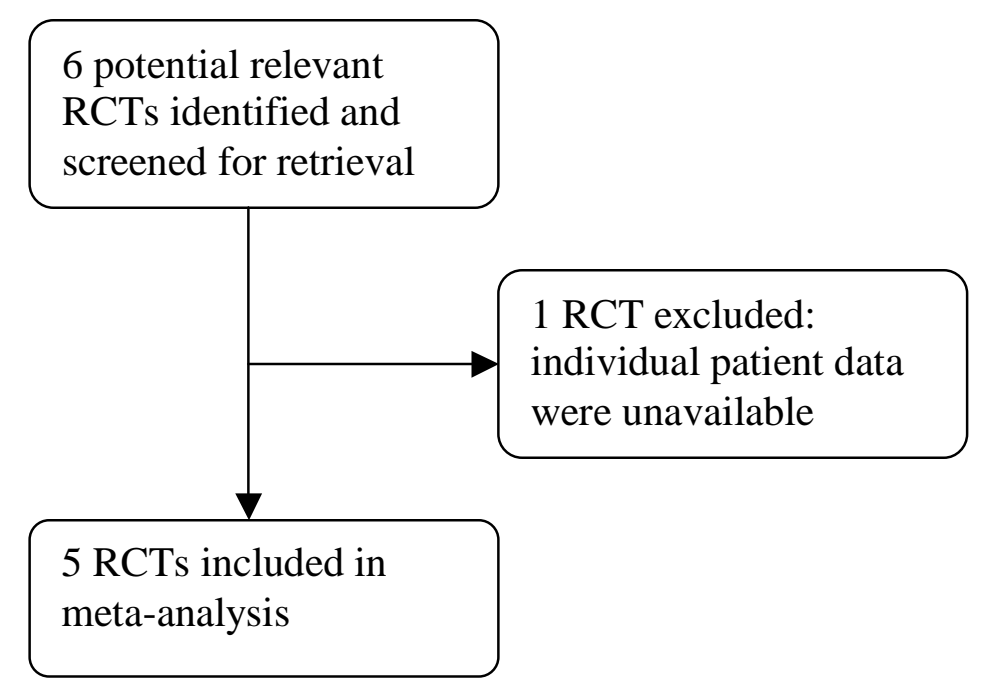


Figure 2. Time-to-event curve for the primary outcome event

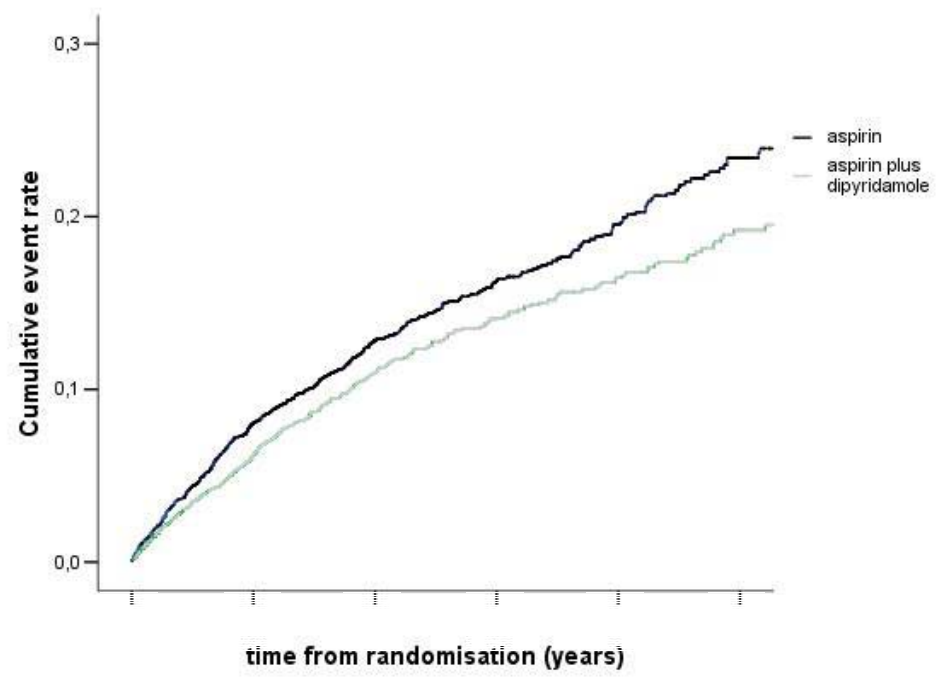


Figure 3. Subgroup analyses according to risk factors

a: number of trials for which the characteristic is known; b: number of patients in subgroup; c: stroke before qualifying event; d: history of ischemic heart disease; e: qualifying event

\section{Subgroup}

Age

Sex

Qualifying event

Hypertension

Diabetes

Stroke ${ }^{c}$

IHD $^{d}$

Aspirin dose

Formulation

dipyridamole

Type of vessel

Interval $Q E^{e}$ -

randomisation

$$
\begin{aligned}
& <65 \text { years } \\
& \geq 65 \text { years }
\end{aligned}
$$

male

female

TIA

stroke

no

yes

no

yes

no

yes

no

yes

$<75 \mathrm{mg}$

$\geq 75 \mathrm{mg}$

immediate

extended

small

large

$<1$ week

1 week-1 month

1-6 months
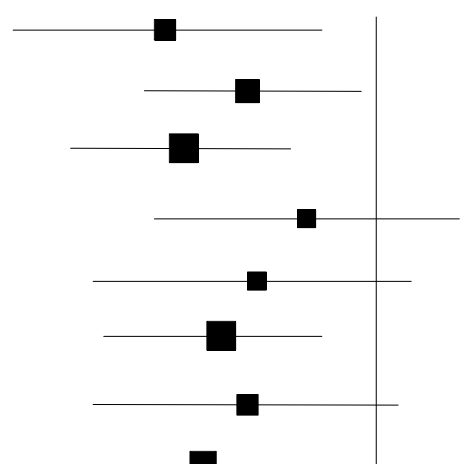

trials $^{a}$ patients ${ }^{b} \mathrm{HR}(95 \% \mathrm{Cl})$

$5 \quad 3545 \quad 0.75(0.61,0.93)$

$5 \quad 4067$

$0.84(0.73,0.98)$

$5 \quad 4810$

$0.77(0.66,0.89)$

$5 \quad 2802$

$5 \quad 2779$

$5 \quad 4829$

$4 \quad 3046$

$4 \quad 4260$

$4 \quad 6108$

$0.91(0.74,1.12)$

$0.85(0.68,1.05)$

$0.81(0.69,0.93)$

$0.84(0.68,1.03)$

$0.79(0.68,0.92)$

$0.81(0.71,0.94)$

$4 \quad 1220$

$0.79(0.61,1.02)$

24786

$0.83(0.70,0.98)$

$2 \quad 1217$

$0.65(0.50,0.85)$

$2 \quad 4501$

$0.73(0.61,0.87)$

$2 \quad 1497$

$0.88(0.70,1.10)$

$5 \quad 4624$

$0.78(0.67,0.92)$

$5 \quad 2988$

$0.87(0.72,1.05)$

$5 \quad 2002$

$0.89(0.71,1.11)$

$5 \quad 5610$

$0.79(0.68,0.91)$

$2 \quad 2645$

$0.77(0.62,0.96)$

$2 \quad 1774$

$0.71(0.55,0.93)$

$2 \quad 839$

$0.87(0.63,1.23)$

$2 \quad 20650.85(0.68,1.07)$

$23093 \quad 0.70(0.57,0.86)$

\section{2}


Figure 4. Subgroup analyses based on risk groups; A: risk groups based on presence of 3 risk factors; B: groups based on DTT-risk model

*: risk on a major vascular event (vascular death, nonfatal stroke or nonfatal myocardial infarction) per year; NNT: numbers needed to treat with aspirin and dipyridamole instead of with aspirin alone to prevent one major vascular event per year; HR: hazard ratio

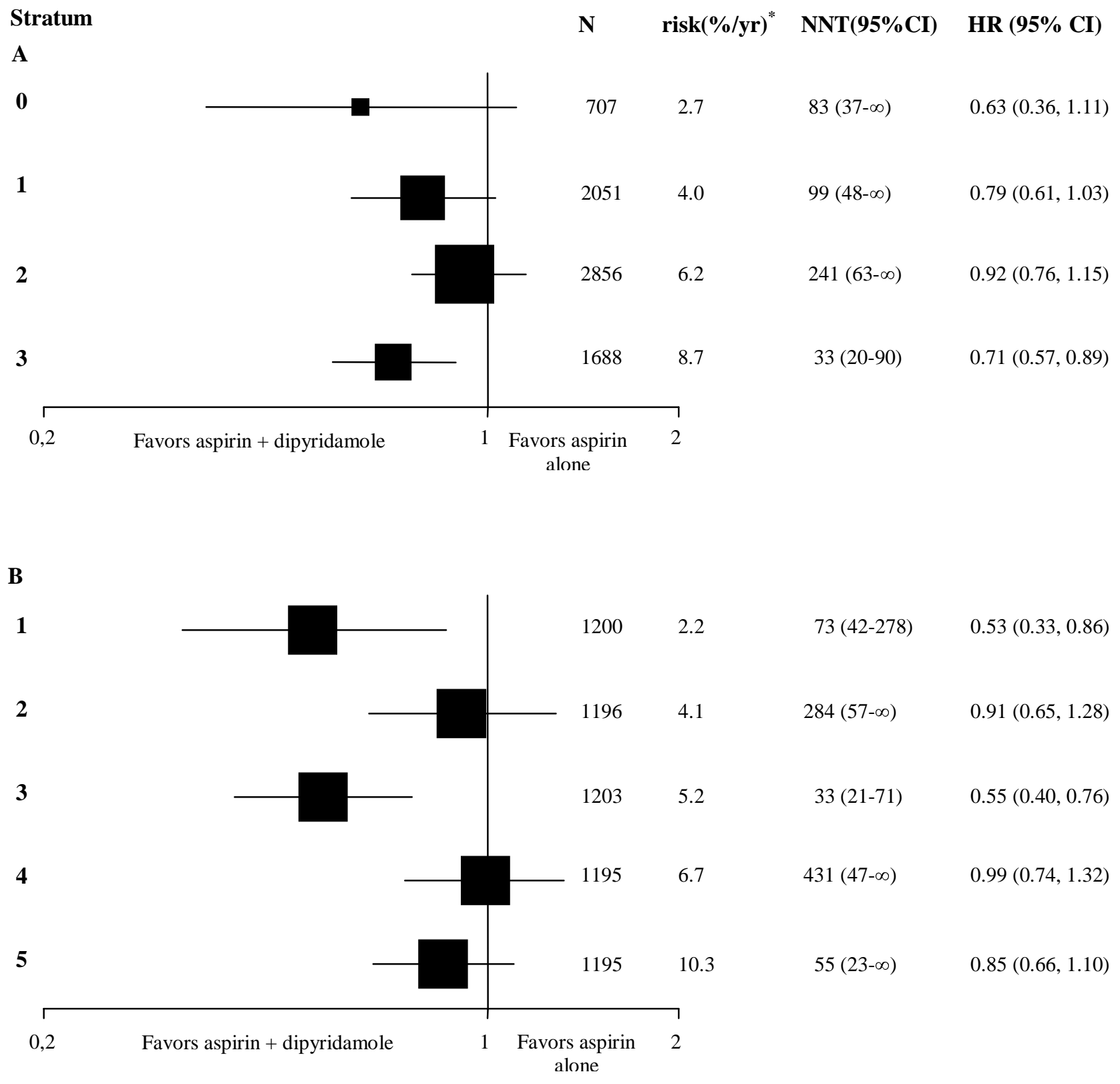

